\title{
Ammonia decomposition over titanium carbides
}

\author{
Jeong-Gil Choi ${ }^{\dagger}$ \\ Department of Nano-Bio Chemical Engineering, Hannam University, Taejon 305-811, Korea \\ (Received September 21, 2012) \\ (Revised October 29, 2012) \\ (Accepted November 2, 2012)
}

\begin{abstract}
Ammonia decomposition over titanium carbides were investigated using eight different samples which have been synthesized by TPR (temperature-programmed reduction) method of titanium oxide $\left(\mathrm{TiO}_{2}\right)$ with pure $\mathrm{CH}_{4}$. The resulting materials which were synthesized using wo different heating rates and space velocity exhibited the different surface areas. These results indicated that the structural properties of these materials have been related to heating rates and space velocity employed. The titanium carbides prepared in this study proved to be active for ammonia decomposition, and the activity changed with the particle size/surface area. These showed the relationship between ammonia decomposition activity and the different active species. Compared to molybdenum carbide, the titanium carbides were one order of magnitude less active, suggesting the correlation between the activity difference and the degree of electron transfer between metals and carbon in metal carbides.
\end{abstract}

Key words Ammonia decomposition activity, Titanium carbides, TPR synthesis method, Relation between surface area and activity

\section{Introduction}

Titanium carbide ( $\mathrm{TiC})$ is one of the transition metal carbides which have been reported to be very active for reaction including $\mathrm{NH}_{3}$ decomposition [1]. CO hydrogenation [2], hydrodenitrogenation [3, 4] and $\mathrm{NH}_{3}$ synthesis [5]. Moreover, it is known that transition metal carbide crystallites such as tungsten and molybdenum carbides crystallites, exhibited activity resemblances of platinumbased crystallites for dehydrogenation, hydrogenolysis and isomerization reactions [6-8]. In particular, for transition metal carbides and nitrides, the structure and stoichiometry of these materials near the surface are known to have influenced the catalytic properties. For example, it have been reported that the catalytic properties of Mo and $\mathrm{W}$ carbides changed with the amount of carbon present in the interstitial sites of the host metal lattice $[9,10]$. Choi et al. [10] have obtained that there is a linear relationship between the pyridine HDN activities over the molybdeum carbides and particle size. These results suggested a structure sensitive reaction for pyridine HDN reaction over Mo carbides. Therefore, they found that the surface stoichiometry might have been correlated with the particle size, showing the different

\footnotetext{
Corresponding author

Tel: +82-42-629-8841

Fax: +82-42-629-8835

E-mail: choi1002@hotmail.com
}

activities. Similar results were obtained from other transition metal carbides. For instance, for vanadium carbides and tantalum carbides which were active for ammonia decomposition, it was found that the reactivity of these materials was explicitly related to the amount of carbon at the surface $[11,12]$. From these results, it should be noted that the surface stoichiometry is one of the functions in determining the catalytic activity of transition metal carbides.

In this paper we prepared eight different titanium carbides by using the temperature-programmed reaction of titanium oxide precursor $\left(\mathrm{TiO}_{2}\right)$ with $\mathrm{CH}_{4}$. The sorptive properties of these materials were obtained using BET total surface area measurements and oxygen chemisorption. We also evaluated the catalytic properties of these materials and compared to that of molybdenum carbides $[11,12]$.

\section{Experimental}

The methods for synthesis and characterization of $\mathrm{Ti}$ carbides were very similar to other transition metal carbides [1, 11, 12]. Titanium carbides used in this study were synthesized vis the TPR (temperature-programmed reduction) of $\mathrm{TiO}_{4}(99.95 \%$, Junsei Chemical Co. Ltd.) with pure $\mathrm{CH}_{4}$, Different heating rates and molar hourly space velocities gave rise to the production of various 
kinds of titanium carbides with different structures and composition. For titanium carbides, two $\mathrm{CH}_{4}$, molar hourly space velocities of 40 and $20 \mathrm{~h}^{-1}$ were used for the synthesis. Here the space velocity is defined as the $\mathrm{CH}_{4}$ molar flow rate divided by the molar amount of $\mathrm{TiO}_{2}$. And two different heating ramps $\left(\beta_{1}, \beta_{2}\right)$ were also used for the temperature increase in this study. The reaction temperature for the synthesis of titanium carbides was increased from room temperature to $800 \mathrm{~K}$ at 250 or $500 \mathrm{~K} / \mathrm{h}$ during the first heating ramp $\left(\beta_{1}\right)$. During the second heating ramp, the temperature was then increased from 800 to $1400 \mathrm{~K}$ at 30 or $60 \mathrm{~K} / \mathrm{h}\left(\beta_{2}\right)$, and held at $1400 \mathrm{~K}$ for an additional hour. After synthesis, the product was quenched to room temperature for passivation and a mixture of $0.5 \% \mathrm{O}_{2}$ in $\mathrm{He}$ (Taedug Gas Co.) flowing at $20 \mathrm{~cm}^{3} / \mathrm{min}$ was used to passivate the sample. This passivation process was continued for another 2 hours, and the product was then removed from the reactor for subsequent analysis. Table 1 shows a summary of the synthesis conditions and surface areas of the titanium carbides.

Nitrogen BET surface areas and oxygen uptakes were measured using a Quantasorb model Chembet 3000 sorption analyzer. Prior to $\mathrm{N}_{2}$ BET surface area measurements, the pretreatment of material was needed so that the sample was isothermally reduced in $\mathrm{H}_{2}\left(20 \mathrm{~cm}^{3} /\right.$ $\min )$ at $673 \mathrm{~K}$ for 3 hours, purged in flowing $\mathrm{He}\left(20 \mathrm{~cm}^{3} /\right.$ min) for 10minutes then cooled to room temperature. Standard single point BET measurements were made at $77 \mathrm{~K}$ using a $30.1 \% \mathrm{~N}_{2}$ in $\mathrm{He}$ mixture (Hanmi Gas Co.). Pulses of purified $\mathrm{N}_{2}(99.998 \%$, Hanmi Gas Co.) were used to calibrate the amount of adsorbed $\mathrm{N}_{2}$. The similar pretreatment conditions were used for oxygen chemisorption measurements. Calibrated volumes of $9.98 \% \mathrm{O}_{2}$ in $\mathrm{He}$ (Hanmi Gas Co.) were injected into

Table 1

Preparation conditions for the titanium carbide crystallites

\begin{tabular}{lllll}
\hline Sample & $\begin{array}{l}\text { Heating rate } \\
\left(\beta_{1}\right)^{\mathrm{a}}(\mathrm{K} / \mathrm{h})\end{array}$ & $\begin{array}{l}\text { Heating rate } \\
\left(\beta_{2}\right)^{\mathrm{b}}(\mathrm{K} / \mathrm{h})\end{array}$ & $\begin{array}{l}\text { Space } \\
\text { velocity }^{\mathrm{c}}\left(\mathrm{h}^{-1}\right)\end{array}$ & $\begin{array}{l}\text { Surface } \\
\text { area }\left(\mathrm{m}^{2} / \mathrm{g}\right)\end{array}$ \\
\hline TiC-1 & 500 & 60 & 40 & 18.3 \\
$\mathrm{TiC}-2$ & 500 & 30 & 40 & 19.8 \\
$\mathrm{TiC}-3$ & 250 & 60 & 40 & 16.9 \\
$\mathrm{TiC}-4$ & 250 & 30 & 40 & 20.8 \\
TiC-5 & 500 & 60 & 20 & 11.4 \\
TiC-6 & 500 & 30 & 20 & 15.6 \\
TiC-7 & 250 & 60 & 20 & 12.6 \\
TiC-8 & 250 & 30 & 20 & 14.3 \\
\hline
\end{tabular}

$\overline{\mathrm{a}, \mathrm{b}}$ Heating rates $\beta_{1}$ and $\beta_{2}$ indicates the linear temperature increases from room temperature to $800 \mathrm{~K}$, and from $800 \mathrm{~K}$ to $1400 \mathrm{~K}$, respectively.

${ }^{\mathrm{c}}$ Ratio of molar flow rate of gas to moles of precursor. the He carrier gas entering the catalyst bed at room temperature until the surface was saturated. The volume of $\mathrm{O}_{2}$ that was not adsorbed, was measured and used to determine the chemisorbed volume.

Before measurements of activity, the sample was reduced using $\mathrm{H}_{2}$ from room temperature to $673 \mathrm{~K}$ at a rate of $0.033 \mathrm{~K} / \mathrm{s}$, held at $673 \mathrm{~K}$ for at least 14 hours then cooled to the reaction temperature. After reduction, atmospheric pressure of $\mathrm{NH}_{3}(99.995 \%)$ was used for $\mathrm{NH}_{3}$ decomposition reaction where the same inlet space velocity based on the bed volume was $7,500 \mathrm{~h}^{-1}$. The activities were measured at temperatures between 633 and $843 \mathrm{~K}$. Due to little changes in the reaction rate observed with the variation of reactant flow rate the external mass transport were considered to be neglected at the present reaction conditions. The reactor effluent was analyzed using an on-line Donam gas chromatograph (DS 6200) equipped with both flame ionization and thermal conductivity detectors. The products were separated using Porapak Q packed columns (80/100, 8' $\times$ $1 / 8 ", \mathrm{CRS})$ connected to a gas chromatography detector.

\section{Results and Discussion}

\subsection{Effects of preparative conditions on surface areas}

The different synthesis conditions produced the various titanium carbides with the BET surface areas ranging from 11.4 to $20.8 \mathrm{~m}^{2} / \mathrm{g}$ (Table 1). From these results it can be seen that the BET surface area of titanium carbides could be affected by preparative conditions. As shown in Table 1 , the heating rates employed in this study during the first and second heating ramps $\left(\beta_{1}\right.$ and $\beta_{2}$ ) had a similar effect on the surface areas. Without exception, the decrease of the heating rate produced titanium carbides with higher surface areas. This effect was applied for eight samples regardless of space velocity used. It is generally known that the heating rate used is related to surface area in the synthesis of transition metal carbides [1, 6, 10]. However, it was also found that there are a negative effect of high heating rate on surface area for the synthesis of vanadium and tantalum carbides using temperature-programmed reaction of their corresponding oxides [11, 12]. One might take into account that the variations of surface area with the heating rate were associated with the solid-state reactions. Therefore, this solid-state reductions finally produce the resultant carbides with different surface areas. In the case of formation of titanium carbides, a molar hourly 
space velocity was proved to be one more significant synthesis condition to produce a different resulting surface areas. For higher space velocities, the high surface area transition metal carbides were generally obtained $[11,12]$. It is considered that the positive effect of space velocity on surface area might be associated with the removal of water vapor produced from the reaction of the titanium oxide with methane.

\subsection{Sorptive properties of Ti carbides}

Table 2 shows the sorptive properties of titanium carbides produced in this study. In order to make an examination of durability the surface areas of fresh and used titanium carbides for ammonia decomposition reaction were measured. For the purpose of obtaining the precise comparison, the pretreatment conditions for used materials were identical with those for fresh materials. The difference in the surface area was not significant within the minimal range of $\sim 15 \%$. Consequently, the comparison of surface areas exhibited that the structure of titanium carbides synthesized in this study were reasonably stable. Table 2 also shows that the surface area of titanium carbides synthesized in this study was 6 or 10 times higher than that of a titanium oxide of the starting material. This result suggested that the structural variation might have been involved in formation of final carbides in the course of reducing process of precursor oxide.

The measurements of oxygen chemisorption uptake of titanium carbides were made at room temperature. The oxygen uptakes for eight samples are shown in Table 2. Fig. 1 shows that the $\mathrm{O}_{2}$ uptake has a linear relation with the BET surface area of titanium carbides. It is

Table 2

Surface areas and oxygen uptakes of titanium carbides ${ }^{\mathrm{a}}$

\begin{tabular}{llllll}
\hline \multirow{2}{*}{ Sample } & \multicolumn{2}{l}{$\begin{array}{l}\text { Surface area } \\
\left(\mathrm{m}^{2} / \mathrm{g}\right)\end{array}$} & $\begin{array}{l}\mathrm{O}_{2} \text { uptake } \\
(\mu \mathrm{mol} / \mathrm{g})\end{array}$ & $\begin{array}{l}\text { Oxygen capacity } \\
\left(\times 10^{13} \text { molecules }\right. \\
\left.\mathrm{O} / \mathrm{cm}^{2}\right)\end{array}$ & $\begin{array}{l}\text { Surface } \\
\text { coverage } \\
(\%)\end{array}$ \\
\cline { 2 - 6 } & Fresh & Used $^{\mathrm{b}}$ & & 1.3 & 1.2 \\
\hline $\mathrm{TiC}-1$ & 18.3 & 15.8 & 2.0 & 1.3 & 0.8 \\
$\mathrm{TiC}-2$ & 19.8 & 15.3 & 1.4 & 0.8 & 1.5 \\
$\mathrm{TiC}-3$ & 16.9 & 16.4 & 2.3 & 1.6 & 1.4 \\
$\mathrm{TiC}-4$ & 20.8 & 19.4 & 2.8 & 1.5 & 0.9 \\
$\mathrm{TiC}-5$ & 11.4 & 10.1 & 0.9 & 0.9 & 2.1 \\
$\mathrm{TiC}-6$ & 15.6 & 12.9 & 2.5 & 1.9 & 1.3 \\
$\mathrm{TiC}-7$ & 12.6 & 10.6 & 1.6 & 1.5 & 1.3 \\
$\mathrm{TiC}^{2} 8$ & 14.3 & 11.2 & 1.7 & 1.4 & - \\
$\mathrm{TiO}_{2}$ & 2.2 & - & - & - &
\end{tabular}

${ }^{\mathrm{a}}$ Based on $\mathrm{O}_{2}$ uptake at $195 \mathrm{~K}$.

${ }^{\mathrm{b}}$ Samples were used for $\mathrm{NH}_{3}$ decomposition.

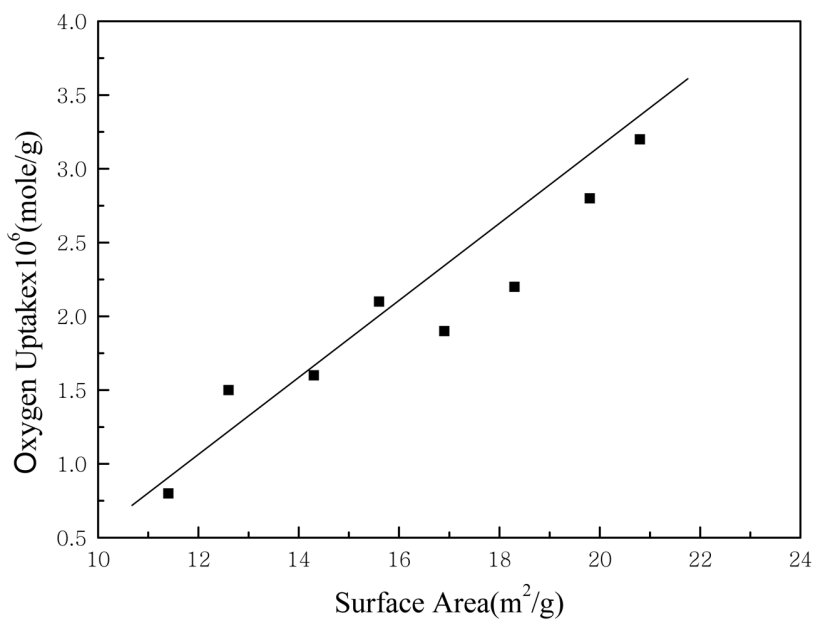

Fig. 1. Oxygen uptakes as a function of surface area for titanium carbides.

general to observe the linear relationship between the $\mathrm{O}_{2}$ uptake and the BET surface area in the area of transition metal carbides. We can see in Table 2 that an oxygen capacity was averaged to be $1.36 \times 10^{13} \mathrm{O} / \mathrm{cm}^{2}$. An assumed surface titanium number density $\left(1.09 \times 10^{15}\right.$ $\mathrm{Ti} / \mathrm{cm}^{2}$ ) gave the average oxygen uptake being equivalent to $\sim 1.31 \%$ surface coverage by atomic oxygen. We compared the sorption properties for titanium carbides to that of molybdenum carbides. It was observed that the oxygen uptakes for titanium carbides were one or two orders of magnitude lower than that for Mo carbide. It was considered that the low uptake values of titanium carbides might be associated to (1) the surface blockage originating from the formation of polymeric carbon and/or (2) residual oxygen at surface. Especially, in the synthesis of transition metal carbides the deposition of polymeric carbon on the product surface may hinder the preparation of metal carbides with high surface area. This hypothesis can be supported by the fact that the amorphous or graphitic carbon during the methane decomposition reaction $\mathrm{CH}_{4} \rightarrow \mathrm{C}+2 \mathrm{H}_{2}$ could be formed on the surface [13].

\subsection{Ammonia decomposition of Ti carbides}

It was observed that titanium carbides synthesized in this study were active for ammonia decomposition reaction. Fig. 2 shows typical ammonia conversion over three titanium carbides (TiC-2, $\mathrm{TiC}-3$ and $\mathrm{TiC}-5)$ as a function of time on stream at $623 \mathrm{~K}$. It can be seen that the fresh catalysts exhibited the highest initial conversion and then gradually lost activity with time. After the activity decreased to the steady-state activities, it remained 


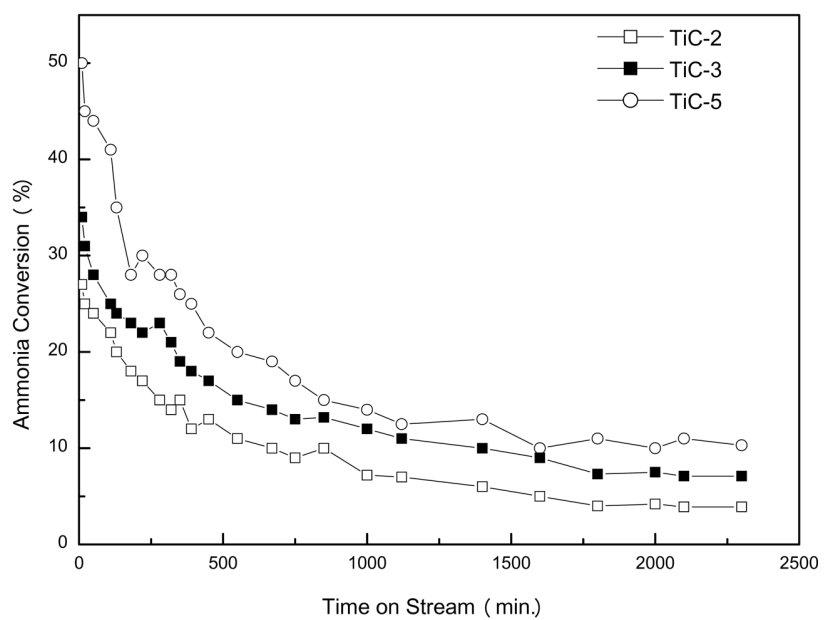

Fig. 2. Typical ammonia conversion (\%) over titanium carbides (TiC-2, TiC-3 and TiC-5) as a function of time on stream at $623 \mathrm{~K}$.

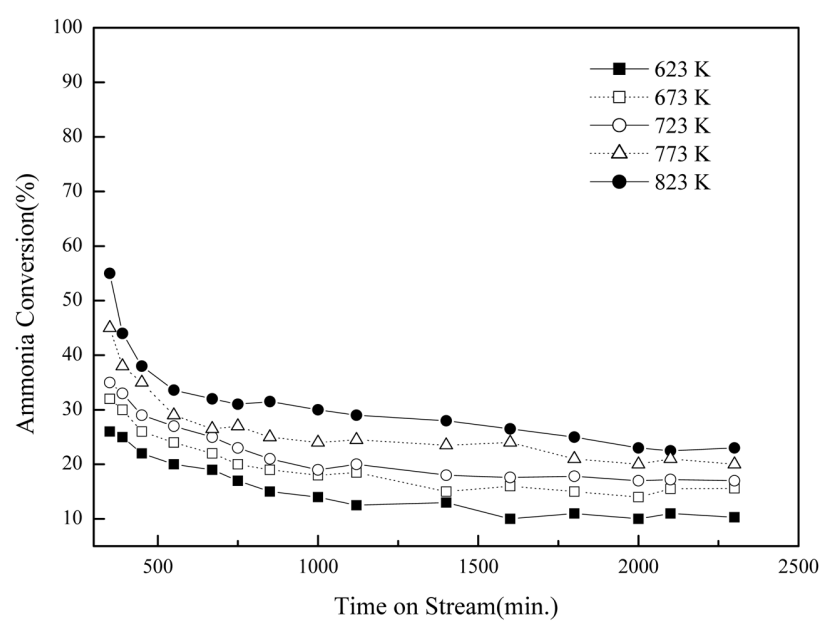

Fig. 3. Typical ammonia conversion (\%) vs. time on stream over titanium carbide (TiC-5) at different temperatures.

constant for a long time. Fig. 3 exhibits typical ammonia conversion (\%) vs. time on stream over titanium carbide (TiC-5) at different temperatures. As the reaction temperature increased, the steady state activities increased for samples in this study.

Table 3 shows a steady state activities for all the titanium carbide catalysts. Among the titanium carbide catalysts, while TiC-5 had the highest steady state activity for $\mathrm{NH}_{3}$ decomposition, TiC-4 shows the lowest one. The catalyst TiC-5 contained $\sim 3.2$ times higher activity than TiC-4. Although all the eight samples prepared in this study have the same bulk structure, the different activity values suggested the formation of the different active species at surface in the titanium carbide catalysts. In fact, the most active titanium carbide catalyst showed the smallest surface area, while the lowest active
Table 3

Conversions of ammonia decomposition for titanium carbide and other metal carbide crystallites

\begin{tabular}{llll}
\hline Sample & $\begin{array}{l}\text { Surface area } \\
\left(\mathrm{m}^{2} / \mathrm{g}\right)\end{array}$ & $\begin{array}{l}\mathrm{O}_{2} \text { uptake } \\
(\mu \mathrm{mol} / \mathrm{g})\end{array}$ & $\begin{array}{l}\text { Conversion } \\
(\%)\end{array}$ \\
\hline $\mathrm{TiC}-1$ & 18.3 & 2.0 & 4.5 \\
$\mathrm{TiC}-2$ & 19.8 & 1.4 & 3.9 \\
$\mathrm{TiC}-3$ & 16.9 & 2.3 & 7.1 \\
$\mathrm{TiC}-4$ & 20.8 & 2.8 & 3.2 \\
$\mathrm{TiC}-5$ & 11.4 & 0.9 & 10.3 \\
$\mathrm{TiC}-6$ & 15.6 & 2.5 & 6.5 \\
$\mathrm{TiC}-7$ & 12.6 & 1.6 & 8.5 \\
$\mathrm{TiC}-8$ & 14.3 & 1.7 & 8.9 \\
$\mathrm{Mo}_{2} \mathrm{C}$ & 35 & 25 & 34 \\
\hline
\end{tabular}

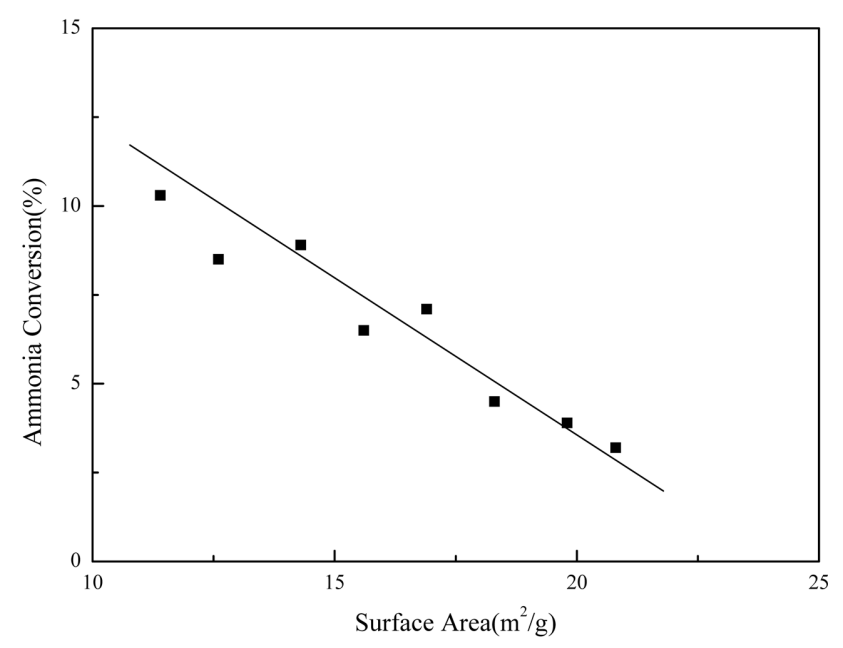

Fig. 4. The conversion versus surface area of titanium carbides.

sample was synthesized with a largest surface area. Fig. 4 showed the relationship between the activity and the surface area, indicating that the activity decreased with the surface area. This kind of linear relationship between the activity and the surface area can be also seen in other carbide catalyst such as vanadium carbide. It was reported that the vanadium carbide catalysts showed the linear relationship between the ammonia decomposition activity and the surface area [11]. They reported that the carbon/vanadium metal ratio at surface might be the reason for that relationship. In other words, the surface area decreased with the decrease of the carbon/vanadium metal ratio. Similarly, the surface properties of titanium carbides were considered to be attributed to the activity results of titanium carbides.

Based on the surface properties of Ti carbides, the differences in activity might be a consequence of differing ammonia bonding geometries. Armstrong et al. found that pyridine adsorbs onto molybdenum nitride catalysts mainly through the nitrogen atom [14]. Similarly, we can 


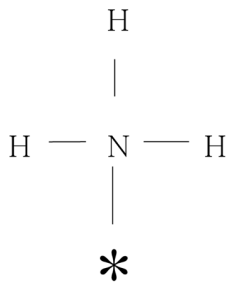

(a)

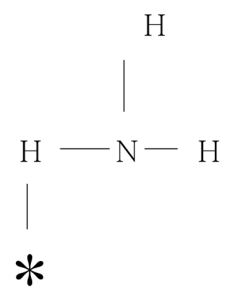

(b)

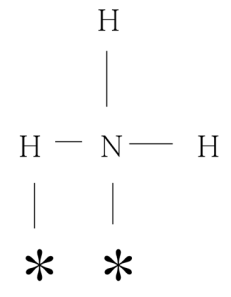

(c)
Fig. 5. Schematic illustrating the plausible geometries for ammonia bonding to the active surface site: (a) "end-on," (b) $\pi$-bound, and (c) $\alpha$-bound. The asterisks in this schematic represents bonding state to a single site for $*$ and multiple sites for $* *$.

assume that ammonia adsorbs onto Ti carbides mainly through the nitrogen atom [10]. This "end-on" bonding geometry is involved in the production of nitrogen and hydrogen by breaking the N-H bonds. While this end-on geometry is primarily responsible for the ammonia decomposition, there are also possible geometries such as $\pi$ bonding and $\alpha$-bonding (Fig. 5). In particular, $\alpha$-bonding is related to multiple active sites.

Table 3 also exhibits a comparison between the catalytic activities of titanium and molybdenum carbides. The activities of titanium carbides were one order of magnitude lower than that of the molybdenum carbide catalyst. The activity difference was considered to be ascribed to the degree of electron transfer between metals and carbon. The electronegativities of Ti and Mo are 1.54 and 2.16, respectively. Therefore, we thought that a larger degree of charge transfer in the vanadiun carbides might be due to the lower activity, which is supported by the previous results in the literature [15].

\section{Conclusions}

Eight titanium carbides was synthesized via TPR (temperature-programmed reduction) of titanium oxide $\left(\mathrm{TiO}_{2}\right)$ with pure $\mathrm{CH}_{4}$. The prepared crystallites contained the different surface areas, indicating that the structural properties of these carbide materials were strong functions of two different heating rates and space velocity employed in the current study. When the space velocity increased, the higher surface area was produced. For titanium carbides, the $\mathrm{O}_{2}$ uptake increases linearly with the increase of BET surface area. The titanium carbide crystallites in this study has proved to be active for ammonia decomposition, indicating that the activity decreased with increasing the surface area. It was also observed that the reactivities of titanium carbide crystallites were ten times lower than that of the molybdenum carbide crystallites.

\section{Acknowledgement}

This paper has been supported by 2011 Sabbatical Year of Hannam University (yeonguyeon) (starting from August 1, 2011 through Sept. 30, 2012).

\section{References}

[1] J.-G. Choi, "Preparation and characterization of niobium carbide crystallites", J. of the Korean Crystal Growth and Crystal Technology 19(3) (2009) 125.

[2] L. leclercq, K. Imura, S. Yoshida, T. Barbee and M. Boudart, "Preparation of catalysts II", edited by Delmon, B., Elsevier, NY. (1978) p. 627.

[3] D.J. Sajkowski and S.T. Oyama, "Symposium on the chemistry of W/Mo catalysis", Prep. Petrol. Chem. Div., 199th ACS Nat. Meeting 35(2) (1990) 233.

[ 4 ] J.-G. Choi, J.R. Brenner, C.W. Colling, B.G. Demczyk, J. Dunning and L.T. Thompson, "Synthesis and characterization of molybdenum nitride hydrodenitrogenation catalysts", Catalysis Today 15 (1992) 201.

[5] L. Volpe and M. Boudart, "Ammonia synthesis on molybdenum nitrides”, J. Phys. Chem. 90 (1986) 4874.

[ 6 ] J.-G. Choi, H.J. Lee, Y.-J. So, Y.-K. Yoon, J.-S. Kim and D.-S. Choi, "Synthesis and catalytic properties of niobium carbides: The effect of synthesis conditions", J. of Sci. Res. Inst. Hannam Univ. 29 (1999) 417.

[7] R.B. Levy and M. Boudart, "Platinum-like behavior of tungsten carbide in surface catalysis", Science 181 (1973) 547.

[ 8 ] J.H. Singelt and D.J.C. Yates, "Transition metal carbides", Nature Phys. Sci. 229 (1971) 27.

[9] L.E. Toth, "Transition metal carbides and nitrides", Academic Press, New York (1971) p. 234.

[10] J.-G. Choi, J.R. Brenner and L.T. Thompson, "Pyridine hydrodenitrogenation over molybdenum carbide catalysts", J. Catal. 154 (1995) 33.

[11] J.-G. Choi, "Effects of experimental conditions on synthesis of titanium carbide crystallites", J. of the Korean Crystal Growth and Crystal Technology 20(2) (2010) 80.

[12] J.-G. Choi, "Synthesis and reactivity over molybdenum carbide crystallites", J. of the Korean Crystal Growth and Crystal Technology 20(2) (2010) 74.

[13] J.-G. Choi, J. Ha and J.-W. Hong, "Synthesis and catalytic properties of vanadium interstitial compounds", Appl. Catal. 168 (1998) 47.

[14] P.A. Armstrong, A.T. Bell and J.A. Reimer, "Comparison of the dynamics and orientation of chemisorbed benzene and oyridine on $\gamma-\mathrm{Mo}_{2} \mathrm{~N}$ ", J. of Phys. Chem. 97 (1993) 1952.

[15] G.V. Samsonov, T.G. Bulankova, P.A. Khodak, E.M. Preshedromirskaya, V.S. Sinelnikova and V.M. Sleptsov, "Catalytic properties of carbides and silicides of transition metals in the dehydrogenation of EthyIbenZene to styrene", Kinet. Katal. 10 (1969) 863. 